\title{
Desenho e validação de iniciadores microssatélites SSR para mamoneira
}

\author{
Edna Lôbo Machado(1) e Simone Alves Silva(1)
}

(1)Universidade Federal do Recôncavo da Bahia, Centro de Ciências Agrárias, Ambientais e Biológicas, Núcleo de Melhoramento Genético e Biotecnologia, Rua Rui Barbosa, no 710, Centro, CEP 44380-000 Cruz das Almas, BA, Brasil. E-mail: ednalobo@ufrb.edu.br, sas@ufrb.edu.br

\begin{abstract}
Resumo - O objetivo deste trabalho foi desenhar, validar e otimizar pares de iniciadores microssatélites SSR para mamoneira. O desenho dos pares de iniciadores foi feito por meio do aplicativo Websat, a partir de sequências depositadas no GenBank do National Center for Biotechnology Information (GenBank/NCBI), e a sua qualidade foi aferida com uso do aplicativo web NetPrimer. Foram utilizadas diferentes concentrações de DNA, cloreto de magnésio, pares de iniciadores, dNTPs e temperatura de anelamento para otimização das condições de PCR. Um total de 30 pares de iniciadores SSR foi desenhado, sintetizado e otimizado. O gel de agarose foi utilizado para deteç̧ão dos produtos amplificados, e o gel desnaturante de poliacrilamida, na otimização das condições de PCR e na identificação de polimorfismo. Os pares de iniciadores apresentaram percentagem média de guanina/citosina (GC) igual a 47,29\% e produtos amplificados com tamanhos entre 128 e $381 \mathrm{pb}$. Vinte e nove pares de iniciadores SSR $(96,7 \%)$ foram validados, dos quais nove foram polimórficos (23,3\%). As concentrações otimizadas para amplificação são: DNA, 25 ng; cloreto de magnésio, 1,2 mmol L-1; iniciadores Forward e Reverse, $0,4 \mathrm{mmol} \mathrm{L}^{-1}$; dNTPs, $0,1 \mathrm{mmol} \mathrm{L}^{-1}$; e temperatura de anelamento, $62 \mathrm{a} 64^{\circ} \mathrm{C}$. As ferramentas de bioinformática Websat e Net Primer podem ser utilizadas para desenvolver iniciadores microssatélites de qualidade, para a mamoneira, a partir de sequências depositadas no GenBank/NCBI.
\end{abstract}

Termos para indexação: Ricinus communis, GenBanK/NCBI, genoma.

\section{Design and validation of SSR microsatellite primers for castor bean}

\begin{abstract}
The objective of this work was to design, validate, and optimize pairs of SSR microsatellite primers for castor bean. The design of the primer pairs was done by means of the Websat application from sequences deposited in the GenBank of the National Center for Biotechnology Information (GenBank/NCBI), and its quality was assessed using the NetPrimer web application. Different concentrations of DNA, magnesium chloride, primer pairs, dNTPs, and annealing temperatures were used for the optimization of PCR conditions. A total of 30 primer pairs were designed, synthesized, and optimized. Agarose gel was used for detection of the amplified products, and denaturing polyacrylamide gel for the optimization of PCR conditions and the identification of polymorphism. The primer pairs presented average guanine/cytosine (GC) percentage of $47.29 \%$ and amplified fragment sizes varying from 128 to $381 \mathrm{bp}$. Twenty-nine pairs of SSR primers $(96.7 \%)$ were validated, of which nine were polymorphic $(23.3 \%)$. The concentrations optimized for amplification are: DNA, $25 \mathrm{ng}$; magnesium chloride, $1.2 \mathrm{mmol} \mathrm{L}^{-1}$; Forward and Reverse primers, $0.4 \mathrm{mmol} \mathrm{L}^{-1}$; dNTPs, $0.1 \mathrm{mmol} \mathrm{L}^{-1}$; and annealing temperature, 62 to $64^{\circ} \mathrm{C}$. The bioinformatic tools Websat and Net Primer can be used to develop quality microsatellite primers for castor bean from sequences deposited at the GenBank/NCBI.
\end{abstract}

Index terms: Ricinus communis, GenBanK/NCBI, genome.

\section{Introdução}

O desenvolvimento de marcadores "simple sequence repeat" (SSR) ou microssatélites, muitas vezes, é a melhor opção para investigar polimorfismos de populações (Foster et al., 2010). Esses marcadores são bastante úteis em estudos de diversidade e mapeamento genético, pois não apenas são locos específicos, mas, também, geram grande número de alelos por loco, apresentam caráter codominante e possibilitam distinguir genótipos proximamente relacionados, o que permite maior eficiência e orientação em futuros cruzamentos, estudos genéticos e seleção assistida por marcadores (Ferreira \& Grattapaglia, 1998).

O grande avanço nos projetos de sequenciamento genético tem possibilitado o desenvolvimento desses marcadores a baixo custo e com maior rapidez. A localização e o desenho dos iniciadores SSR são 
realizados por meio de programas computacionais que identificam sequências SSR, a exemplo do aplicativo Websat (Martins et al., 2009).

Com o avanço das técnicas de "next generation sequencing" (NGS), o sequenciamento do genoma de espécies de interesse econômico tem viabilizado, a custos relativamente baixos, o desenvolvimento de iniciadores capazes de amplificar regiões ricas em microssatélites.

Embora o sequenciamento do genoma da mamoneira (Ricinus communis L.) já tenha sido realizado (Chan et al., 2010), até o momento, o número de microssatélites disponíveis para a espécie é baixo para o mapeamento de QTLs, com um total de 51 pares de iniciadores SSR (Bajay et al., 2009, 2011; Seo et al., 2011) e 118 EST-SSR (Qiu et al., 2010). Assim, é necessário o desenvolvimento e a otimização de mais iniciadores SSR para saturação do genoma da mamoneira.

De acordo com Markoulatos et al. (2002), a validação de uma reação de PCR, principalmente quando se trata de um par de iniciadores, requer, em geral, planejamento estratégico. O sucesso na reação de PCR está relacionado à concentração relativa dos pares de iniciadores, à concentração do tampão, ao equilíbrio de cloreto de magnésio, às concentrações dos desoxiribonucleotídeos, à quantidade do DNA e da Taq, bem como à temperatura de anelamento $(\mathrm{Ta})$.

O objetivo deste trabalho foi desenhar, validar e otimizar pares de iniciadores microssatélites SSR para mamoneira.

\section{Material e Métodos}

Foram utilizadas as sequências do genoma de mamoneira que se encontram depositadas no GenBank do National Center for Biotechnology Information NCBI (National Center for Biotechnology Information, 2013), no formato Fasta, para a identificação de regiões SSR. A identificação das regiões genômicas contendo os microssatélites e os desenhos dos pares de iniciadores que flanqueiam essas regiões foram feitos com uso do aplicativo Websat (Martins et al., 2009). Os parâmetros utilizados na identificação dos SSRs foram os seguintes: SSR compostos por motivos dinucleotídeos com, no mínimo, sete repetições por motivo; SSR compostos por motivos tri, tetra e pentanucleotídeos com, no mínimo, cinco repetições; e
SSR compostos por hexanucleotídeos com, no mínimo, três repetições do motivo.

Para padronizar as reações de PCR, utilizaramse os seguintes critérios na seleção dos pares de iniciadores: produto final da amplificação no intervalo de 150 a $300 \mathrm{pb}$, que é um tamanho compatível com eletroforese em géis de poliacrilamida a $7 \%$, corados com nitrato de prata; tamanhos dos iniciadores entre 19 e $22 \mathrm{pb}$; percentagem de GC no intervalo de 40 a $60 \%$; e temperatura média entre 55 e $62^{\circ} \mathrm{C}$, com diferença máxima de $1^{\circ} \mathrm{C}$ entre os iniciadores de cada par.

A qualidade do desenho dos iniciadores, que flanqueiam as regiões microssatélites, foi verificada por meio do aplicativo NetPrimer (Premier Biosoft, 2013). Os mais adequados, livres de grampos, dímeros, dímeros cruzados, sequências palindromas e repetições de nucleotídeos, foram selecionados para as reações de PCR, em um total de 30 pares de iniciadores.

Para o teste de amplificação das regiões genômicas contendo os SSRs da mamoneira e a otimização das reações de PCR, utilizou-se o DNA das cultivares BRS Nordestina, EBDA MPA 17 e Sipeal 28, disponibilizadas pela Empresa Baiana de Desenvolvimento Agrícola (EBDA) e já estabelecidas em condições de campo na Universidade Federal do Recôncavo da Bahia. Para o isolamento do DNA genômico, foram realizadas coletas de folhas jovens e saudáveis das três cultivares. Esse material foi desinfestado em solução de hipoclorito de sódio a $20 \%$, enxaguado com água destilada e armazenado em ultrafreezer, a $-80^{\circ} \mathrm{C}$, até o momento da extração de DNA.

A extração de DNA das três cultivares foi realizada segundo o protocolo descrito por Doyle \& Doyle (1990). A quantidade e a qualidade de DNA foram avaliadas por análise comparativa com concentrações conhecidas de DNA lambda (Invitrogen, Carlsbad, CA, EUA) em gel de agarose a $0,8 \%$, corado com brometo de etídeo $\left(0,5 \mathrm{mg} \mathrm{mL}^{-1}\right)$. As amostras foram diluídas em tampão Tris-EDTA, para ajuste de sua concentração $\left(5 \mathrm{ng} \mu \mathrm{L}^{-1}\right)$.

Os pares de iniciadores SSR (Forward e Reverse) desenhados foram sintetizados, na escala de $25 \mathrm{nmol}$ (Invitrogen, Carlsbad, CA, EUA) e utilizados na amplificação das regiões SSR de mamoneira.

Utilizou-se um total de cinco misturas para as reações de PCR - contendo diferentes concentrações de DNA, cloreto de magnésio, iniciadores Forward e Reverse, e 
dNTPs - e de sete temperaturas de anelamento, para as três cultivares (Tabela 1).

As amplificações do DNA das três cultivares, BRS Nordestina, EBDA MPA 17 e Sipeal 28, com os pares de iniciadores SSR desenhados, foram conduzidas em termociclador Biocycler MJ96+/MJ96G (Applied Biosystems do Brasil Ltda., São Paulo, SP) com temperatura de desnaturação inicial de $94^{\circ} \mathrm{C}$ por $1 \mathrm{~min}$, seguida de 35 ciclos de amplificação $\left[94^{\circ} \mathrm{C}\right.$ por $1 \mathrm{~min}$, temperatura de anelamento $\left(55\right.$ a $\left.64^{\circ} \mathrm{C}\right)$ por $1 \mathrm{~min}$ e $72^{\circ} \mathrm{C}$ por $1 \mathrm{~min}$ ] e extensão final de $72^{\circ} \mathrm{C}$ por $10 \mathrm{~min}$ (Bajay et al., 2011).

Para a avaliação da amplificação com as diferentes misturas, os produtos da PCR foram submetidos, primeiramente, à eletroforese em gel de agarose a 3\%, corado com brometo de etídeo $\left(0,5 \mathrm{mg} \mathrm{mL}^{-1}\right)$. O gel de agarose foi primeiramente utilizado na verificação da amplificação das regiões SSR, por se tratar de um gel mais rápido e menos laborioso. Esses produtos foram visualizados por meio de luz UV e fotografados em sistema de fotodocumentação (Kodak Digital Science, Kodak, Rochester, NY, EUA).

Para a eliminação das bandas fantasmas e inespecíficas e uma melhor análise dos pares de iniciadores polimórficos, foi feita a otimização das reações da PCR e da temperatura de anelamento. Procedimento semelhante foi adotado por Oliveira (2006) e Bajay (2009), que utilizaram gel de agarose, para visualização dos produtos amplificados, e gel desnaturante de poliacrilamida para otimização das reações de PCR e detecção de polimorfismo. Os produtos amplificados foram submetidos à eletroforese em gel desnaturante de poliacrilamida a

Tabela 1. Concentrações dos componentes das misturas e temperaturas de anelamento utilizadas na validação dos pares de iniciadores, para as cultivares BRS Nordestina, EBDA MPA 17 e Sipeal 28 de mamoneira (Ricinus communis) ${ }^{(1)}$.

\begin{tabular}{lccccc}
\hline Mistura & $\begin{array}{c}\text { DNA } \\
(\mathrm{ng})\end{array}$ & $\begin{array}{c}\mathrm{MgCl}_{2} \\
\left(\mathrm{mmol} \mathrm{L}^{-1}\right)\end{array}$ & $\begin{array}{c}\text { Iniciadores F } \\
\mathrm{e} \mathrm{R}\left(\mathrm{mmol} \mathrm{L}^{-1}\right)\end{array}$ & $\begin{array}{c}\text { dNTPs } \\
\left(\mathrm{mmol} \mathrm{L}^{-1}\right)\end{array}$ & $\begin{array}{c}\text { Temperaturas de } \\
\text { anelamento }\left({ }^{\circ} \mathrm{C}\right)\end{array}$ \\
\hline 1 & 50 & 1,5 & 0,8 & 0,1 & $\begin{array}{c}55,58,60,61,62, \\
63 \mathrm{e} 64\end{array}$ \\
2 & 50 & 1,3 & 0,8 & 0,1 & $\begin{array}{c}55,58,60,61,62, \\
63 \mathrm{e} 64\end{array}$ \\
3 & 25 & 1,2 & 0,4 & 0,08 & $\begin{array}{c}55,58,60,61,62, \\
63 \mathrm{e} 64\end{array}$ \\
4 & 25 & 1,0 & 0,4 & 0,08 & $\begin{array}{c}55,58,60,61,62, \\
63 \mathrm{e} 64\end{array}$ \\
5 & 25 & 1,2 & 0,4 & 0,1 & $\begin{array}{c}55,58,60,61,62, \\
63 \mathrm{e} 64\end{array}$ \\
\hline
\end{tabular}

${ }^{(1)} \mathrm{F}$, forward; R, reverse; dNTPs, desoxinucleotídeos trifosfatados.
$7 \%$, conforme protocolo proposto por Litt et al. (1993). O gel foi corado com nitrato de prata (Creste et al., 2001).

Para a confirmação do tamanho esperado dos fragmentos, utilizou-se o padrão de peso molecular de 50 pb (Invitrogen, São Paulo, SP). Após seco, o gel foi digitalizado com scanner HP ScanJet N8460, (Hewlett-Packard Company, Palo Alto, CA, EUA).

Em relação à qualidade da amplificação, foram observados dois aspectos: o primeiro refere-se ao número de locos originados, visto que o par de iniciadores pode amplificar locos únicos ou múltiplos; o segundo diz respeito à presença de bandas "stutter" ou fantasmas (Pereira, 2010). Já em relação ao polimorfismo, os locos foram caracterizados como polimórficos ou monomórficos, em razão da existência de alelos distintos entre as cultivares utilizadas.

\section{Resultados e Discussão}

Um total de 30 pares de iniciadores SSR foi desenhado por meio do vasculhamento do genoma da mamoneira por microssatélites (Tabela 2), com percentagem média de GC igual a 47,29\%. Esse resultado foi próximo ao encontrado por Bajay (2009) em 41 pares de iniciadores SSR, para mamoneira, com percentagem média de GC de 47,56\%.

Os tamanhos dos produtos amplificados, por meio dos pares de iniciadores, variaram de 128 a $381 \mathrm{pb}$. Apenas o par de iniciadores RcoM30 amplificou um produto acima de $300 \mathrm{pb}$; os demais amplificaram produtos abaixo desse valor. Bajay et al. (2009), Qiu et al. (2010) e Bajay et al. (2011), respectivamente, também obtiveram, por meio de marcadores microssatélites, para mamoneira, produtos de amplificação cujo tamanho variou entre 100 e 300,130 e 288,170 e 320.

Os marcadores SSR foram classificados como perfeitos $(76,7 \%$, dos quais $30,0,30,0,6,7$ e $10,0 \%$ com repetições de di, tri, tetra e hexanucleotídeos, respectivamente) ou compostos (23,3\%). Resultados semelhantes foram obtidos por Bajay (2009), que desenvolveu 41 pares de iniciadores para mamoneira, dos quais $70,73 \%$ foram classificados como perfeitos; $19,51 \%$, como compostos; e apenas $9,75 \%$ como interrompidos.

$\mathrm{Na}$ amplificação das regiões microssatélites de mamoneira, a quinta mistura foi a que gerou quantidades de produtos suficientes para visualização 
Tabela 2. Iniciadores SSR desenhados a partir de sequências do genoma de mamoneira (Ricinus communis) depositadas no GenBank/NCBI ${ }^{(1)}$.

\begin{tabular}{|c|c|c|c|c|c|c|c|c|}
\hline Denominação & Sequência 5'-3' & $\begin{array}{l}\mathrm{Ta} \\
\left({ }^{\circ} \mathrm{C}\right)\end{array}$ & $\begin{array}{l}\mathrm{GC} \\
(\%)\end{array}$ & Motivo & $\begin{array}{c}\text { Produtos } \\
(\mathrm{pb})\end{array}$ & Tipo de repetição & $\begin{array}{l}\text { № de } \\
\text { alelos }\end{array}$ & Contig \\
\hline RcoM01 & $\begin{array}{l}\text { F: GACGGGATGAAAGAGGATA } \\
\text { R: TGGCTGCTGTTGTTACTCTA }\end{array}$ & 63 & $\begin{array}{c}47,37 \\
45\end{array}$ & $(\mathrm{TA})_{18}$ & 277 & Dinucleotídeos & 1 & 1100012341095 \\
\hline RcoM02 & $\begin{array}{l}\text { F: ATGTCTGCTCTTGGTCTGTC } \\
\text { R: ATGGTATGGTTTTGATGAGG }\end{array}$ & 64 & $\begin{array}{l}50 \\
40\end{array}$ & $(\mathrm{CT})_{14}$ & 185 & Dinucleotídeos & 3 & 1100012341095 \\
\hline RcoM03 & $\begin{array}{l}\text { F: ATGACCCCTTTGATGTGCTC } \\
\text { R: GGCAGGTTTTGGACTCGTTA }\end{array}$ & 62 & $\begin{array}{l}50 \\
50\end{array}$ & $\begin{array}{c}(\mathrm{TA})_{18} \mathrm{e} \\
(\text { AATAAA })_{2}\end{array}$ & 234 & $\begin{array}{l}\text { Composto dinucleotídeos } \\
\text { e hexanucleotídeos }\end{array}$ & 1 & 1100012360932 \\
\hline RcoM04 & $\begin{array}{l}\text { F: CATAACCAACTCCTCACCAGA } \\
\text { F: TTGTGATCGTTGTGGCTTGT }\end{array}$ & 62 & $\begin{array}{c}45,45 \\
45\end{array}$ & $\begin{array}{l}(\mathrm{TCCTAC})_{2} \mathrm{e} \\
(\mathrm{GGTAGG})_{2}\end{array}$ & 274 & $\begin{array}{c}\text { Composto } \\
\text { hexanucleotídeos }\end{array}$ & 1 & 1100012360932 \\
\hline RcoM05 & $\begin{array}{l}\text { F: ATGAGTCGCAATCTATGAACG } \\
\text { R: ATGGTGGAAGAGAATGGCTG }\end{array}$ & 62 & $\begin{array}{c}40,91 \\
50\end{array}$ & $(\mathrm{AAAAGA})_{3}$ & 204 & Hexanucleotídeos & 2 & 1100012361640 \\
\hline RcoM06 & $\begin{array}{l}\text { F: GTTCCAACTCCCAAACAGAC } \\
\text { R: GCTCTTACCTACTCCTCCCC }\end{array}$ & 64 & $\begin{array}{c}40,91 \\
50\end{array}$ & $(\mathrm{AAAAGA})_{3}$ & 204 & Hexanucleotídeos & 1 & 1100012355638 \\
\hline RcoM07 & $\begin{array}{l}\text { F: CGGGTGAGAAGCAAGAGAAG } \\
\text { R: TACAAGCCAAATAGTGCCCC }\end{array}$ & 63 & $\begin{array}{l}55 \\
50\end{array}$ & $(\text { TTAATT })_{3}$ & 205 & Hexanucleotídeos & 1 & 1100012360398 \\
\hline RcoM08 & $\begin{array}{l}\text { F: GCTATCCACATTGGTTCCCT } \\
\text { R: AAGTTTTGGTGATGGCTGCT }\end{array}$ & 63 & $\begin{array}{l}50 \\
45\end{array}$ & $(\mathrm{GAA})_{5}$ & 237 & Trinucleotídeos & 1 & 1100012361169 \\
\hline RcoM09 & $\begin{array}{l}\text { F: GGCATTTTGGGAACTTGTGT } \\
\text { R: AATGGTCTAATCCCCGCTCT }\end{array}$ & 62 & $\begin{array}{l}45 \\
50\end{array}$ & $(\mathrm{AT})_{8}$ & 211 & Dinucleotídeos & 1 & 1100012361169 \\
\hline RcoM10 & $\begin{array}{l}\text { F: GGGCGGGCTCTGTAAAGTA } \\
\text { R: TTACCCAAACACCCTCTCCA }\end{array}$ & 62 & $\begin{array}{c}57,89 \\
50\end{array}$ & $(\mathrm{TA})_{15}$ & 259 & Dinucleotídeos & 1 & 1100012358159 \\
\hline RcoM11 & $\begin{array}{l}\text { F: AACATCCCCTCCACTCACAG } \\
\text { R: CCTGACCCTCCTGATTGTTC }\end{array}$ & 63 & $\begin{array}{l}55 \\
55\end{array}$ & $(\mathrm{CAA})_{6}$ & 252 & Trinucleotídeos & 2 & 1100012358159 \\
\hline RcoM12 & $\begin{array}{l}\text { F: GATTGGGGAGTGCGATAGA } \\
\text { R: CAGCAATATACACCATGACAA }\end{array}$ & 62 & $\begin{array}{l}52,63 \\
40,91\end{array}$ & $\begin{array}{l}(\mathrm{TAT})_{7} \mathrm{e} \\
(\mathrm{TTA})_{11}\end{array}$ & 189 & Composto trinucleotídeos & 1 & 1100012358159 \\
\hline RcoM13 & $\begin{array}{l}\text { F: TCAGATGCGATTGAGAGTCCT } \\
\text { R: CCTTTGATGGCTTATTGCGT }\end{array}$ & 62 & $\begin{array}{c}47,62 \\
45\end{array}$ & $(\mathrm{TAT})_{8}$ & 136 & Trinucleotídeos & 1 & 1100012357797 \\
\hline RcoM14 & $\begin{array}{l}\text { F: ATGAAAAGGAAATGGAGTGG } \\
\text { R: AGTGAGGGTTGTATGGGGAG }\end{array}$ & 62 & $\begin{array}{c}42,86 \\
55\end{array}$ & $(\mathrm{TAT})_{16}$ & 176 & Trinucleotídeos & 1 & 1100012359304 \\
\hline RcoM15 & $\begin{array}{l}\text { F: ATGGAGGTCTTGTGAGGTGC } \\
\text { R: AGCCCCTTCCTTGTAGTTTTG }\end{array}$ & 62 & $\begin{array}{c}55 \\
47,62\end{array}$ & $(\mathrm{GAA})_{5}$ & 176 & Trinucleotídeos & 1 & 1100012360867 \\
\hline RcoM16 & $\begin{array}{l}\text { F: GGGGTATCCTTATGCTCCAAC } \\
\text { R: CCAAACTCAAGACATTCATCA }\end{array}$ & 62 & $\begin{array}{c}50 \\
40,91\end{array}$ & $(\mathrm{AAGA})_{7}$ & 220 & Tetranucleotídeos & 1 & 1100012360867 \\
\hline RcoM17 & $\begin{array}{l}\text { F: AAGATTCACAACACCCCATAA } \\
\text { R: GCAGAAGAAAGAAAAGGCA }\end{array}$ & 63 & $\begin{array}{l}40,91 \\
42,86\end{array}$ & $\begin{array}{l}(\mathrm{GAA})_{8} \text { e } \\
(\mathrm{GA})_{13}\end{array}$ & 248 & $\begin{array}{l}\text { Composto tri e } \\
\text { dinucleotídeos }\end{array}$ & 3 & 1100012357074 \\
\hline RcoM18 & $\begin{array}{l}\text { F: CCTGCGTTATCTGTTGTTGC } \\
\text { R: GGGTCTTGAGCCAGGTTGTA }\end{array}$ & 62 & 5055 & $(\mathrm{AATA})_{5}$ & 245 & Tetranucleotídeos & 1 & 1100012362951 \\
\hline RcoM19 & $\begin{array}{l}\text { F: TCATTCACTTCACTTCTTGTCC } \\
\text { R: TCAAAGATTGGTTAGAGGTCAG }\end{array}$ & 64 & $\begin{array}{l}40,91 \\
40,91\end{array}$ & $(\mathrm{CT})_{18}$ & 298 & Dinucleotídeos & 1 & 1100012358350 \\
\hline RcoM20 & $\begin{array}{l}\text { F: GCCGACGCATAAGGTAAGAG } \\
\text { R: TCTCAACAAACACACCCACG }\end{array}$ & 63 & $\begin{array}{l}55 \\
50\end{array}$ & $(\mathrm{GAA})_{13}$ & 128 & Trinucleotídeos & 2 & 1100012356588 \\
\hline RcoM21 & $\begin{array}{l}\text { F: CGGAACGACGACAAGAAAG } \\
\text { R: GTTATGGAAGGGAAAAGAAAG }\end{array}$ & 63 & $\begin{array}{l}40,91 \\
52,63\end{array}$ & $(\mathrm{AAG})_{12}$ & 253 & Trinucleotídeos & 2 & 1100012358097 \\
\hline RcoM22 & $\begin{array}{l}\text { F: TTCACCCGCTATTCTCAACC } \\
\text { R: CTCAACGACTTCCCTCCAAA }\end{array}$ & 62 & $\begin{array}{l}50 \\
50\end{array}$ & $(\mathrm{ACT})_{5}$ & 227 & Trinucleotídeos & 2 & 1100012357261 \\
\hline RcoM23 & $\begin{array}{l}\text { F: CCTTTTGGAGGGTCCTTAGC } \\
\text { R: CGCATCCTTTCATTCTCTTCTT }\end{array}$ & 63 & $\begin{array}{c}55 \\
40,91\end{array}$ & $(\mathrm{AG})_{18}$ & 283 & Dinucleotídeos & 1 & 1100012362318 \\
\hline RcoM24 & $\begin{array}{l}\text { F: ACTTCATTGCCCTTGGACAC } \\
\text { R: TTAGGGAGATTGAGGACTGATG }\end{array}$ & 62 & $\begin{array}{c}50 \\
45,45\end{array}$ & $\begin{array}{l}(\mathrm{AT})_{10} \text { e } \\
(\mathrm{TG})_{7}\end{array}$ & 159 & $\begin{array}{l}\text { Composto } \\
\text { dinucleotídeos }\end{array}$ & - & 1100012362318 \\
\hline RcoM25 & $\begin{array}{l}\text { F: TCACTAACACAACAAGACGGA } \\
\text { R: GAACGCAAAAGATTGGTCA }\end{array}$ & 62 & $\begin{array}{l}42,86 \\
42,11\end{array}$ & $(\mathrm{TAT})_{12}$ & 232 & trinucleotídeos & 1 & 1100012356175 \\
\hline RcoM26 & $\begin{array}{l}\text { F: TGTAAAAGTTGAGGGGTGGAA } \\
\text { R: GGAAGAAGTGACAGATGGTGC }\end{array}$ & 63 & $\begin{array}{l}42,86 \\
52,38\end{array}$ & $(\mathrm{AT})_{7}$ & 264 & Dinucleotídeos & 1 & 1100012359260 \\
\hline RcoM27 & $\begin{array}{l}\text { F: TCAAGTGACAAAGGACACATCT } \\
\text { R: GTGACAGAATCAGCCTAAACC }\end{array}$ & 63 & $\begin{array}{l}40,91 \\
47,62\end{array}$ & $(\mathrm{AG})_{20}$ & 287 & Dinucleotídeos & 2 & 1100012288376 \\
\hline RcoM28 & $\begin{array}{l}\text { F: TTGGGTGTTATCCTCATTCC } \\
\text { R: GAGAAGAAGAAAGAAAAGGTG }\end{array}$ & 63 & $\begin{array}{c}45 \\
40,91\end{array}$ & $\begin{array}{l}(\mathrm{GAA})_{6},(\mathrm{AGA})_{5} \\
\quad \mathrm{e}(\mathrm{AAG})_{6}\end{array}$ & 215 & Composto trinucleotídeos & 2 & 1100012358069 \\
\hline RcoM29 & $\begin{array}{l}\text { F: AACAAAACTCGCTCACCCAT } \\
\text { R: AAGCGTCCAAAAGCAAAGAA }\end{array}$ & 63 & $\begin{array}{l}45 \\
40\end{array}$ & $(\mathrm{AG})_{19}$ & 250 & Dinucleotídeos & 1 & 1100012356181 \\
\hline RcoM30 & $\begin{array}{l}\text { F: TCCAAAATATAAGCCCTGCC } \\
\text { R: TGGTCTGTTCTAAGCAATCCC }\end{array}$ & 63 & $\begin{array}{c}45 \\
47,62\end{array}$ & $\begin{array}{l}(\mathrm{CT})_{17} \mathrm{e} \\
(\mathrm{TA})_{25}\end{array}$ & 381 & Composto dinucleotídeo & 1 & 1100012356181 \\
\hline
\end{tabular}

${ }^{(1)} \mathrm{Ta}$, temperatura de anelamento; GC, guanina/citosina; Contig, região cromossômica contendo os SSRs; F, forward; R, reverse. 
em gel de agarose e gel de poliacrilamida (Tabela 1). A temperatura de anelamento variou entre 62 e $64^{\circ} \mathrm{C}$, de acordo com cada par de iniciadores (Tabela 2). Para Bajay et al. (2009), a reação de PCR que amplificou regiões microssatélites em mamoneira, em outros 11 pares de iniciadores, foi composta de $50 \mathrm{ng}$ de DNA genômico, 1,5 $\mathrm{mmol} \mathrm{L}^{-1}$ de cloreto de magnésio, $0,8 \mathrm{mmol} \mathrm{L}^{-1}$ de cada iniciador (Forward e Reverse), 0,15 $\mathrm{mmol} \mathrm{L}^{-1}$ de cada dNTP, $1 \mathrm{U}$ de Taq DNA polimerase, $1 \mathrm{X}$ de tampão $\left(50 \mathrm{mmol} \mathrm{L}^{-1}\right.$ de tris-HCL, $20 \mathrm{mmol} \mathrm{L}^{-1}$ de KCL) e temperatura de anelamento de $60^{\circ} \mathrm{C}$, para todos os 11 pares de iniciadores.

De um total de 30 pares de iniciadores SSR desenhados, 29 (96,7\%) foram validados com sucesso por meio da PCR, ou seja, amplificaram regiões genômicas da mamoneira, em gel de agarose (Figura 1) e em gel desnaturante de poliacrilamida (Figura 2). Somente o par de iniciadores RcoM24 não amplificou as amostras. Os produtos visualizados em gel de agarose não apresentaram bandas fantasmas e inespecíficas e nem polimorfismo entre as cultivares (Figura 1). Entretanto, bandas fantasmas e inespecíficas e polimorfismo foram observados em gel desnaturante de poliacrilamida (Figura 2). Essa diferença entre os géis está de acordo com Pinto et al. (2001). Segundo os autores, os produtos de amplificação de DNA podem ser visualizados em géis de agarose ou desnaturantes de poliacrilamida. Contudo, géis desnaturantes de poliacrilamida permitem separação de fragmentos que diferem em apenas um par de bases, enquanto géis de agarose apresentam um limite de resolução acima de quatro pares de bases.

Os vinte e nove locos amplificados, à temperatura de anelamento de $62^{\circ} \mathrm{C}$, apresentaram locos únicos e ausência de bandas fantasmas em gel de agarose. No entanto, em gel desnaturante de poliacrilamida, $13(44,8 \%)$ apresentaram locos únicos e sem bandas fantasmas e 16 apresentaram bandas

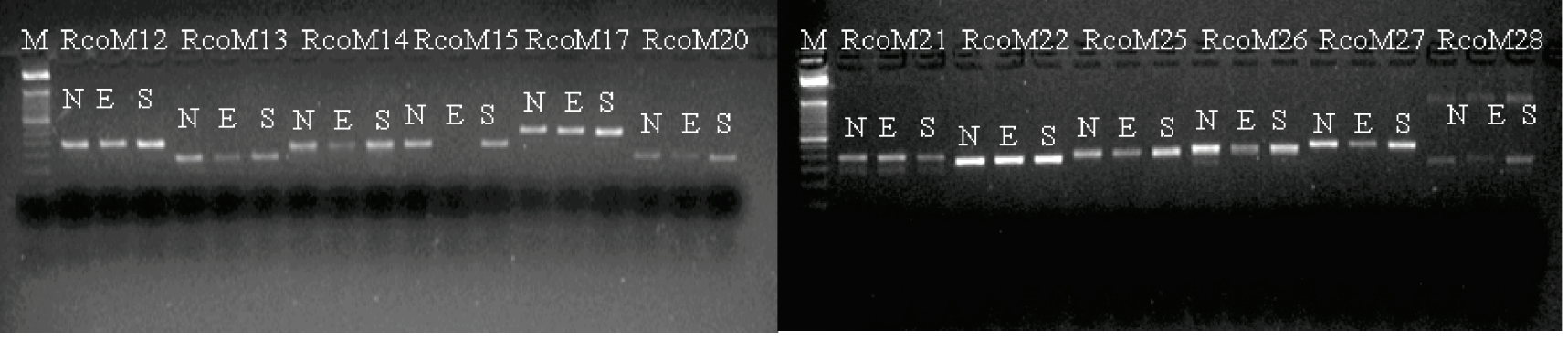

Figura 1. Gel de agarose com locos SSR, das cultivares BRS Nordestina (N), EBDA MPA 17 (E) e Sipeal 28 (S) de mamoneira (Ricinus communis), amplificados à temperatura de anelamento de $62^{\circ} \mathrm{C}$. M, marcador ladder de $50 \mathrm{pb}$.

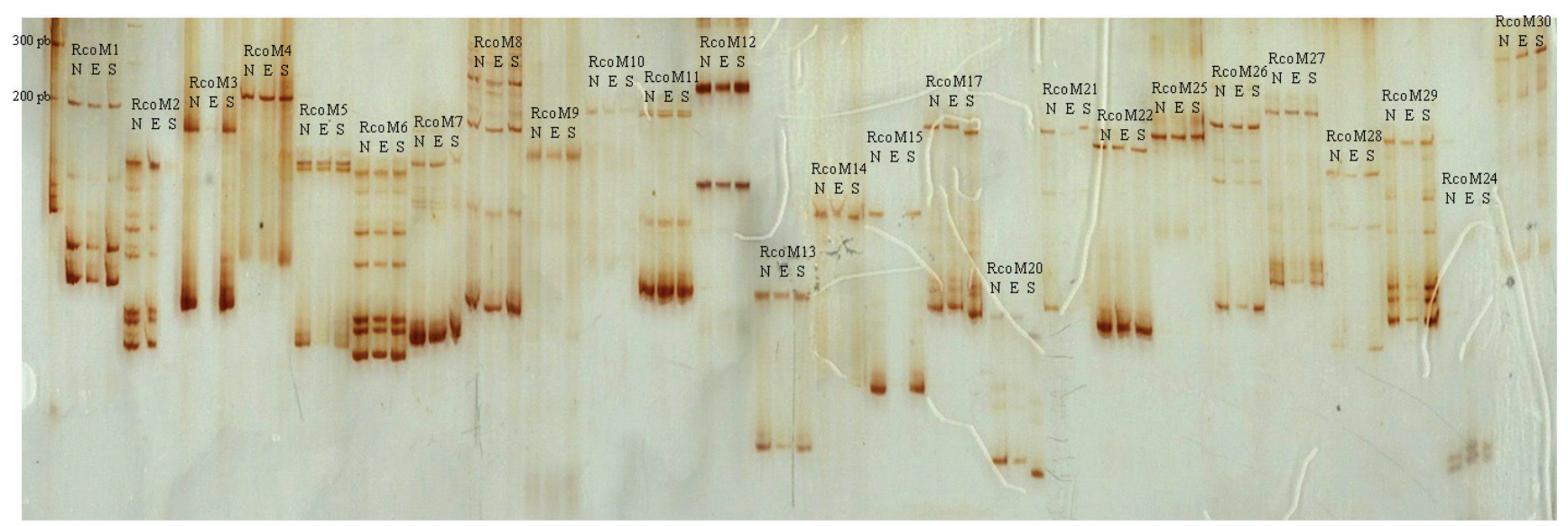

Figura 2. Gel desnaturante de poliacrilamida com locos SSR, das cultivares BRS Nordestina (N), EBDA MPA 17 (E) e Sipeal 28 (S) de mamoneira (Ricinus communis), amplificados à temperatura de anelamento de $62^{\circ} \mathrm{C}$. M, marcador ladder de $50 \mathrm{pb}$. 
fantasmas $(55,2 \%)$. Estas bandas não foram detectadas em gel desnaturante de poliacrilamida com o aumento da temperatura de anelamento $\left(63\right.$ e $\left.64^{\circ} \mathrm{C}\right)$ para os pares de iniciadores (Tabela 2). Esses resultados são indicativos de que a otimização da temperatura de anelamento dos pares de iniciadores é passo importante para a amplificação de regiões genômicas específicas, livres de amplificações inespecíficas e bandas fantasmas.

Nove pares de iniciadores (23,3\%) - RcoM2, RcoM5, RcoM11, RcoM17, RcoM20, RcoM21, RcoM22, RcoM27 e RcoM28 - foram eficientes na identificação de polimorfismo, para as três cultivares analisadas (Figura 2).

Em trabalho realizado por Qiu et al. (2010), de 379 pares de iniciadores EST-SSR utilizados na amplificação de 24 acessos de mamoneira, 118 foram polimórficos (31,13\%). Bajay (2009) utilizou 41 pares de iniciadores na genotipagem de 120 genótipos e obteve $63,41 \%$ de pares de iniciadores polimórficos.

A diferença entre a percentagem de locos polimórficos encontrada no presente trabalho e por Bajay (2009) pode ser explicada pelo maior número de genótipos analisados por este autor, que avaliou acessos de um banco de germoplasma e não de cultivares já estabelecidas, como as aqui avaliadas.

Vinte pares de iniciadores foram monomórficos e, provavelmente, não são úteis para a análise de polimorfismo entre as cultivares BRS Nordestina, EBDA MPA 17 e Sipeal 28. Entretanto, esses pares de iniciadores podem ser testados, quanto à detecção de polimorfismos, em um maior número de genótipos de mamoneira.

\section{Conclusões}

1. É possível desenvolver iniciadores microssatélites de qualidade, para a mamoneira, a partir de sequências depositadas no GenBank/NCBI e da utilização das ferramentas de bioinformática Websat e Net Primer.

2. As concentrações ajustadas para amplificação são: DNA, $25 \mathrm{ng}$; cloreto de magnésio, 1,2 mmol L-1; iniciadores Forward e Reverse, 0,4 $\mathrm{mmol} \mathrm{L}^{-1}$ de cada um; dNTPs, $0,1 \mathrm{mmol} \mathrm{L}^{-1}$; e temperatura de anelamento, 62 a $64^{\circ} \mathrm{C}$, de acordo com cada par de iniciadores.

3. O gel de agarose a $3 \%$ é eficiente na detecção dos produtos amplificados, e o gel desnaturante de poliacrilamida é eficiente na otimização das condições da PCR e na detecção de polimorfismo entre as cultivares.

4. Nove pares de iniciadores (RcoM2, RcoM5, RcoM11, RcoM17, RcoM20, RcoM21, RcoM22, RcoM27 e RcoM28) são polimórficos para as cultivares BRS Nordestina, EBDA MPA 17 e Sipeal 28.

\section{Agradecimentos}

À Petrobrás Biocombustível e à Agência Nacional do Petróleo, Gás Natural e Biocombustíveis (ANP), pelo apoio financeiro.

\section{Referências}

BAJAY, M.M. Desenvolvimento de marcadores microssatélite e caracterização do banco de germoplasma de mamona (Ricinus communis L.). 2009. 96p. Dissertação (Mestrado) - Escola Superior de Agricultura Luiz de Queiroz, Piracicaba.

BAJAY, M.M.; PINHEIRO, J.B.; BATISTA, C.E.A.; NOBREGA, M.B.M.; ZUCCHI, M.I. Development and characterization of microsatellite markers for castor (Ricinus communis L.), an important oleaginous species for biodiesel production. Conservation Genetic Resource, v.1, p.237-239, 2009. DOI 10.1007/s12686-009-9058-z.

BAJAY, M.M.; ZUCCHI, M.I.; KIIHL, T.A.M.; BATISTA, C.E.A.; MONTEIRO, M.; PINHEIRO, J.B. Development of a novel set of microsatellite markers for castor bean, Ricinus communis (Euphorbiaceae). American Journal of Botany, v.98, e87-e89, 2011. DOI: 10.3732/ajb.1000395.

CHAN, A.P.; CRABTREE, J.; ZHAO, Q.; LORENZI, H.; ORVIS, J.; PUIU, D.; MELAKE-BERHAN, A.; JONES, K.M.; REDMAN, J.; CHEN, G.; CAHOON, E.B.; GEDIL, M.; STANKE, M.; HAAS, B.J.; WORTMAN, J.R.; FRASER-LIGGETT, C.M.; RAVEL, J.; RABINOWICZ, P.D. Draft genome sequence of the oilseed species Ricinus communis. Nature Biotechnology, v.28, p.951-956, 2010. DOI: $10.1038 /$ nbt.1674.

CRESTE, S.; TULMANN NETO, A.; FIGUEIRA, A. Detection of single sequence repeat polymorphisms in denaturing polyacrylamide sequencing gels by silver staining. Plant Molecular Biology Reporter, v.19, p.299-306, 2001. DOI: 10.1007/BF02772828.

DOYLE, J.J.; DOYLE, J.L. Isolation of plant DNA from fresh tissue. Focus, v.12, p.13-15, 1990.

FERREIRA, M.E.; GRATTAPAGLIA, D. Introdução ao uso de marcadores moleculares em análise genética. 3.ed. Brasília: Embrapa-Cenargen, 1998. 220p. (Embrapa-Cenargen. Documentos, 20).

FOSTER, J.T.; ALLAN, G.J.; CHAN, A.P.; RABINOWICZ, P.D.; RAVEL, J.; JACKSON, P.J.; KEIM, P. Single nucleotide polymorphisms for assessing genetic diversity in castor bean (Ricinus communis). BMC Plant Biology, v.10, 2010. DOI: 10.1186/1471-2229-10-13. 
LITT, M.; HAUGE, X.; SHARMA, V. Shadow bands seen when typing polymorphic dinucleotide repeats: some causes and cures. BioTechniques, v.15, p.280-284, 1993.

MARKOULATOS, P.; SIAFAKAS, N.; MONCANY, M. Multiplex polymerase chain reaction: a practical approach. Journal of Clinical Laboratory Analysis, v.16, p.47-51, 2002. DOI: 10.1002/ jcla.2058.

MARTINS, W.S.; LUCAS, D.C.S.; NEVES, K.F. de S.; BERTIOLI, D.J. WebSat - a web software for microsatellite marker development. Bioinformation, v.3, p.282-283, 2009. DOI: 10.6026/97320630003282.

NATIONAL CENTER FOR BIOTECHNOLOGY INFORMATION. NCBI shotgun assembly sequences: Genome (WGS) and Transcriptome (TSA). Available at: <http://www.ncbi. nlm.nih.gov/Traces/wgs/?val=AASG02>. Accessed on: 1 Dec. 2013 .

OLIVEIRA, E.J. de. Desenvolvimento e uso de marcadores microssatélites para construção e integração de mapas genéticos de maracujá-amarelo (Passiflora edulis Sims F. flavicarpa Deg.). 2006. 152p. Tese (Doutorado) - Escola Superior de Agricultura Luiz de Queiroz, Piracicaba.
PEREIRA, G. da S. Desenvolvimento de marcadores SSR, M-AFLP e SNP visando à integração de mapas genético-moleculares de Passiflora alata Curtis. 2010. 154p. Dissertação (Mestrado) - Escola Superior de Agricultura Luiz de Queiroz, Piracicaba.

PINTO, L.R.; VIEIRA, M.L.C.; SOUZA, A.P. de; SOUZA JUNIOR, C.L. de. Isoenzimas e microssatélites em plantas. Biotecnologia Ciência e Desenvolvimento, n.20, p.16-19, 2001.

PREMIER BIOSOFT. NetPrimer. Available at: <http:// www.premierbiosoft.com/netprimer/>. Accessed on: 1 Dec. 2013.

QIU, L.; YANG, C.; TIAN, B.; YANG, J.; LIU, A. Exploiting EST databases for the development and characterization of EST-SSR markers in castor bean (Ricinus communis L.). BMC Plant Biology, v.10, 2010. DOI: 10.1186/1471-2229-10-278.

SEO, K.-I.; LEE, G.-A.; MA, K.-H.; HYUN, D.-Y.; PARK, Y.-J.; JUNG, J.-W.; LEE, S.-Y.; GWAG, J.-G.; KIM, C.-K.; LEE, M.-C. Isolation and characterization of 28 polymorphic SSR loci from castor bean (Ricinus communis L.). Journal of Crop Science and Biotechnology, v.14, p.97-103, 2011. DOI: 10.1007/ s12892-010-0107-7.

Recebido em 27 de junho de 2013 e aprovado em 28 de outubro de 2013

Pesq. agropec. bras., Brasília, v.48, n.11, p.1457-1463, nov. 2013 